\title{
Polar patches observed by ESR and their possible origin in the cusp region
}

\author{
A. M. Smith, S. E. Pryse, L. Kersley \\ Department of Physics, University of Wales, Aberystwyth, SY23 3BZ, UK
}

Received: 14 January 2000 / Revised: 29 May 2000 / Accepted: 26 June 2000

\begin{abstract}
Observations by the EISCAT Svalbard radar in summer have revealed electron density enhancements in the magnetic noon sector under conditions of IMF $B z$ southward. The features were identified as possible candidates for polar-cap patches drifting anti-Sunward with the plasma flow. Supporting measurements by the EISCAT mainland radar, the CUTLASS radar and DMSP satellites, in a multi-instrument study, suggested that the origin of the structures lay upstream at lower latitudes, with the modulation in density being attributed to variability in soft-particle precipitation in the cusp region. It is proposed that the variations in precipitation may be linked to changes in the location of the reconnection site at the magnetopause, which in turn results in changes in the energy distribution of the precipitating particles.
\end{abstract}

Key words: Ionosphere (ionosphere-magnetosphere interactions; plasma temperature and density; polar ionosphere)

\section{Introduction}

Long-lived enhancements of ionospheric plasma, known as polar patches, drift in the anti-Sunward convection flow across the polar cap. A comprehensive review of the current understanding of the patch phenomenon has been given by Crowley (1996). Patches occur predominantly under conditions of IMF $B z$ southward and drift across the polar cap at speeds of typically 300$1000 \mathrm{~ms}^{-1}$ (Buchau et al., 1983). They have been observed in summer and winter (Buchau and Reinisch, 1991) and have been seen to form in geomagnetically

Correspondence to: S. E. Pryse

e-mail: sep@aber.ac.uk conjugate regions (Rodger et al., 1994a). The modelling study of Sojka et al. (1994) indicated the presence of patches in all seasons with their occurrence modulated by UT. Pederson et al. (1998) observed patch structures on horizontal scales of some $200-300 \mathrm{~km}$ using the Sondrestrom incoherent scatter radar, while Walker et al. (1999) imaged a patch-like structure of latitudinal dimension some $2.5^{\circ}$ using radio tomography.

Several different mechanisms have been proposed for patch formation. Most processes rely on the transport of dayside ionisation from lower latitudes, through the convection throat region into the polar cap. One group of studies suggests that the ionisation produced by solar radiation at the lower latitudes becomes entrained into the high-latitude convection pattern. For example, Buchau et al. (1985) reported patch densities comparable to those in regions of solar ionisation at dayside subauroral latitudes. Subsequent work suggested that the plasma is convected in a tongue of ionisation that extends from subauroral latitudes into the polar cap (Valladares et al., 1994). Sojka et al. (1993) demonstrated, in a modelling study, that the fragmentation into patches may occur by shearing of the ionisation tongue as a consequence of temporal variations in the IMF $B y$ component. An alternative mechanism suggested by Rodger et al. (1994b) proposed the break-up of the tongue as a consequence of the enhanced recombination rate for plasma loss in the high velocities of flow channel events. In another study Lockwood and Carlson (1992) proposed that patches were created when solar ionisation was captured by the polar convection during the pulsed reconnection of flux transfer events. The initial expansion of the polar cap on the dayside entrained solar-produced ionisation of high density with the subsequent contraction taking the photo-ionisation into the cross-polar flow. Particle precipitation has also been cited as a possible source of patch plasma. Weber et al. (1984) suggested that, if the flux-tube convected Sunward along the cusp for tens of minutes before turning anti-Sunward into the polar cap, then there might be sufficient time for build-up of ionisation. Modelling studies by Sojka and Schunk (1986) indicated that 
densities might increase by a factor of two above background within a flux tube that convected through cusp-precipitation for some 10-15 min. An electron density enhancement within the cusp region, with characteristics consistent with those of a polar patch, was observed by Walker et al. (1999) using radio tomography. Auroral observations confirmed that soft precipitation had played an important role in the creation of this structure at an altitude where the enhanced plasma densities would be expected to have sufficiently long lifetimes to preserve the patch in the cross-polar flow.

The current study presents observations made by the EISCAT Svalbard radar (ESR) of a succession of three enhancements in electron density found in the magnetic noon sector between 0810 and 0840 UT on 22 August 1998 that have characteristics consistent with polar patches. Simultaneous observations by several instruments, including the CUTLASS and EISCAT mainland radars and DMSP satellite particle detectors, have been used to identify the source of the enhanced ionisation and to deduce a possible mechanism by which the plasma may have been structured into patches.

\section{Observations}

\subsection{EISCAT Svalbard radar}

The EISCAT Svalbard radar $\left(78.2^{\circ} \mathrm{N}, 16.1^{\circ} \mathrm{E}, 75.0^{\circ}\right.$ MLAT, $113.1^{\circ} \mathrm{MLON}$ ) was operating with its beam aligned along the geomagnetic field in the $\mathrm{F}$ layer, as part of the OMOT UK Special Programme experiment. Electron densities and temperatures measured between 0800 UT and $0840 \mathrm{UT}$, post-integrated over $30 \mathrm{~s}$ intervals, are shown in the upper and lower panels of Fig. 1 respectively. The electron densities were initially below $1.0 \times 10^{11} \mathrm{~m}^{-3}$. These low densities may be a consequence of an ion heating event that is outside the scope of the current study. The densities in the $\mathrm{F}$ layer increased shortly after 0805 UT with magnitudes doubling by about 0810 UT. Three clear enhancements
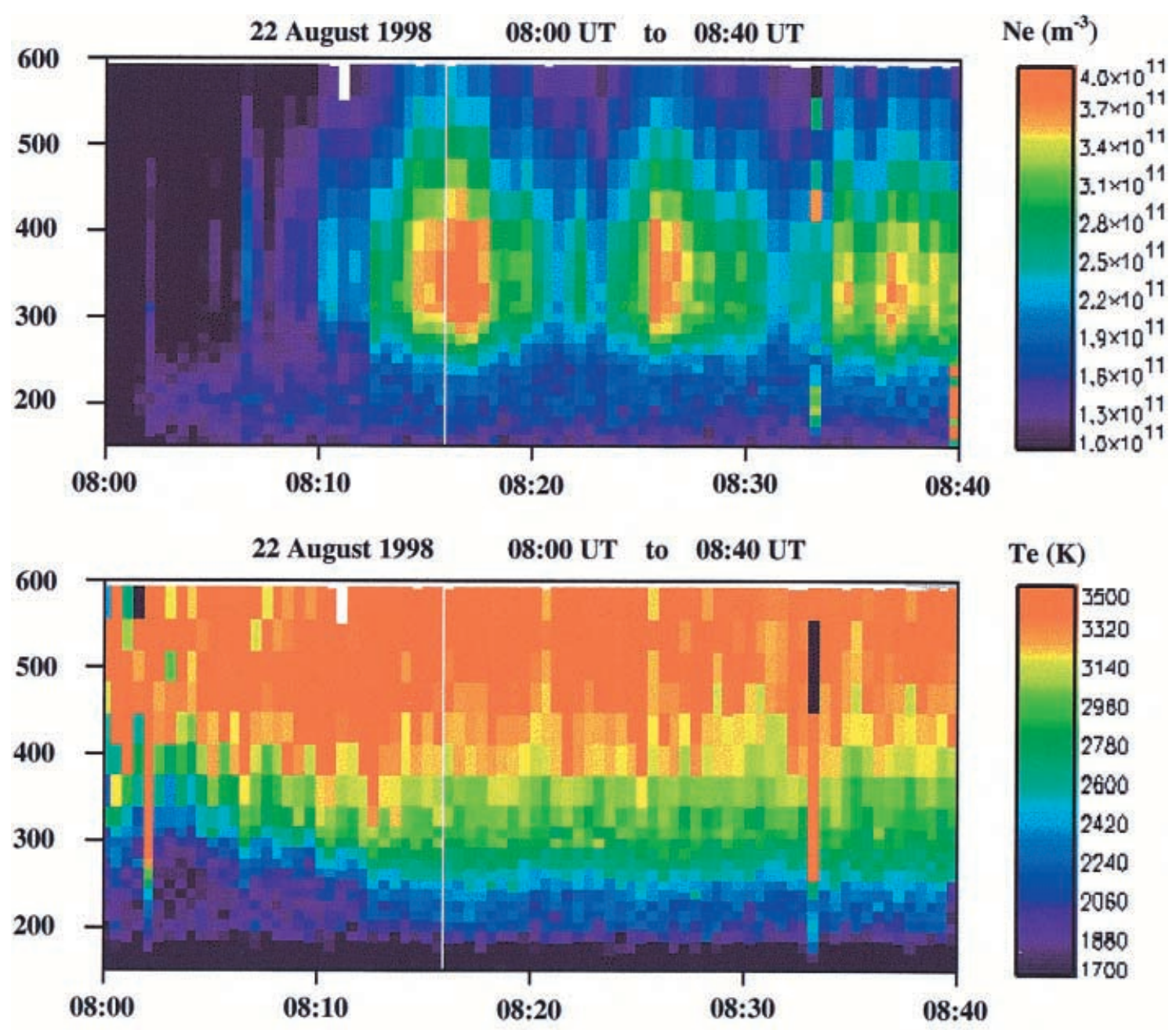

Time (UT)

Fig. 1. Electron densities (upper panel) and electron temperatures (lower panel) measured by the ESR radar between 0800 and 0840 UT observing with the beam aligned along the geomagnetic field in the $\mathrm{F}$ region 
are seen in the record with a peak altitude near $350 \mathrm{~km}$, while between the features the densities reduce to a background level of about $2.0 \times 10^{11} \mathrm{~m}^{-3}$. The maximum density in the first enhancement is approximately $4.0 \times 10^{11} \mathrm{~m}^{-3}$, with concentrations in excess of $2.8 \times 10^{11} \mathrm{~m}^{-3}$ being maintained for $8 \mathrm{~min}$. A similar maximum is attained in the second enhancement but the duration of densities above $2.8 \times 10^{11} \mathrm{~m}^{-3}$ is reduced to some $6 \mathrm{~min}$. The maximum density is less in the third feature, though enhanced values are maintained for a longer time interval that may extend beyond the end of the useful record. The electron temperatures below $350 \mathrm{~km}$ are cooler between 0800 and 0810 UT than at the later times of interest to the current study. Figure 2 shows line plots of the electron density at an altitude of $344 \mathrm{~km}$ (upper panel) and electron temperatures at 344 and $248 \mathrm{~km}$ (lower panel) between 0800 and 0840 UT. The lower temperatures at the earlier times can be attributed to the ion frictional heating event (McCrea et al., 1995). The temperatures measured after 0810 UT do not show any temporal structure corresponding to the three intervals of increased densities, which suggests that the ionisation enhancements were not produced in situ by ongoing precipitation. Indeed the relative uniformity of the electron temperature indicates that the density enhancements seen in Fig. 1 comprised cold plasma convecting through the radar beam. The conclusion that there was no structured precipitation is reinforced by the high altitude of the enhancements and their sharp bottomside vertical profile, with plasma having recombined at the lower altitudes but remaining at high altitudes where the lifetime is longer.
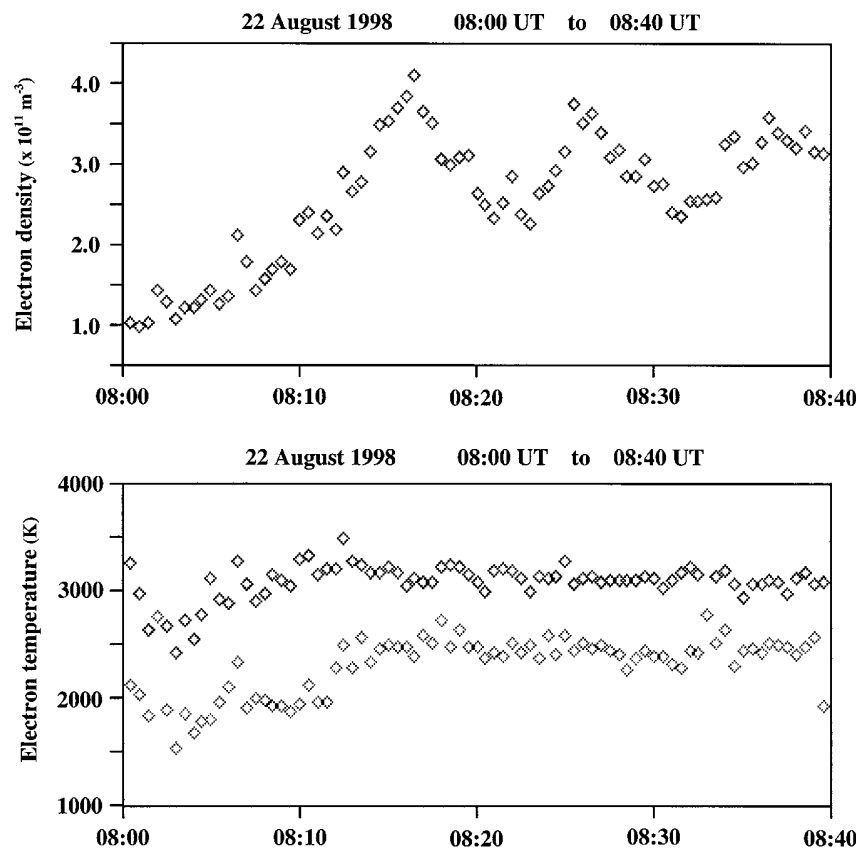

Fig. 2. Electron densities at an altitude of $344 \mathrm{~km}$ (upper panel) and electron temperatures at altitudes of $344 \mathrm{~km}$ and $248 \mathrm{~km}$ (upper and lower traces respectively in the lower panel) measured by the ESR radar between 0800 and 0840 UT observing with the beam aligned along the geomagnetic field in the $\mathrm{F}$ region

\subsection{Interplanetary Magnetic Field}

The three components of the IMF measured by the ACE satellite from 0630 UT to 0830 UT are shown in the three panels of Fig. 3. The $B z$ component was negative throughout the time interval, signifying conditions for equatorial reconnection. The value of $B z$ was about $-10 \mathrm{nT}$ at the start of the interval but, following a few excursions on time scales of about $10 \mathrm{~min}$, it levelled near $-5 \mathrm{nT}$ after $0740 \mathrm{UT}$. The $B y$ component was positive throughout, apart from a very minor reversal shortly after 0640 UT, and did not show evidence of the fluctuations on time scales $\sim 10 \mathrm{~min}$. The polarity of $B x$ changed from weakly positive to negative, but of particular note are the excursions in the component between 0700 and 0740 UT that appear to be anti-correlated with those in $B z$. The ACE satellite was located at approximately $250 R e$ upstream of the Earth in the solar wind. Simple calculation estimates the time delay between the satellite observation and the ionospheric response to be $75 \mathrm{~min}$, although this value should be treated with caution because of the large distance between the satellite observations and the ionosphere and the uncertainties in the solar wind features along this distance.

\subsection{DMSP satellite passes}

A pass of the DMSP F14 satellite traversed the region of interest at approximately 0830 UT. The measured ion and electron flux spectra in the two lower panels of Fig. 4 show characteristic features of cusp precipitation (Newell and Meng, 1988), with ion energies $\sim 10^{3} \mathrm{eV}$ and electron
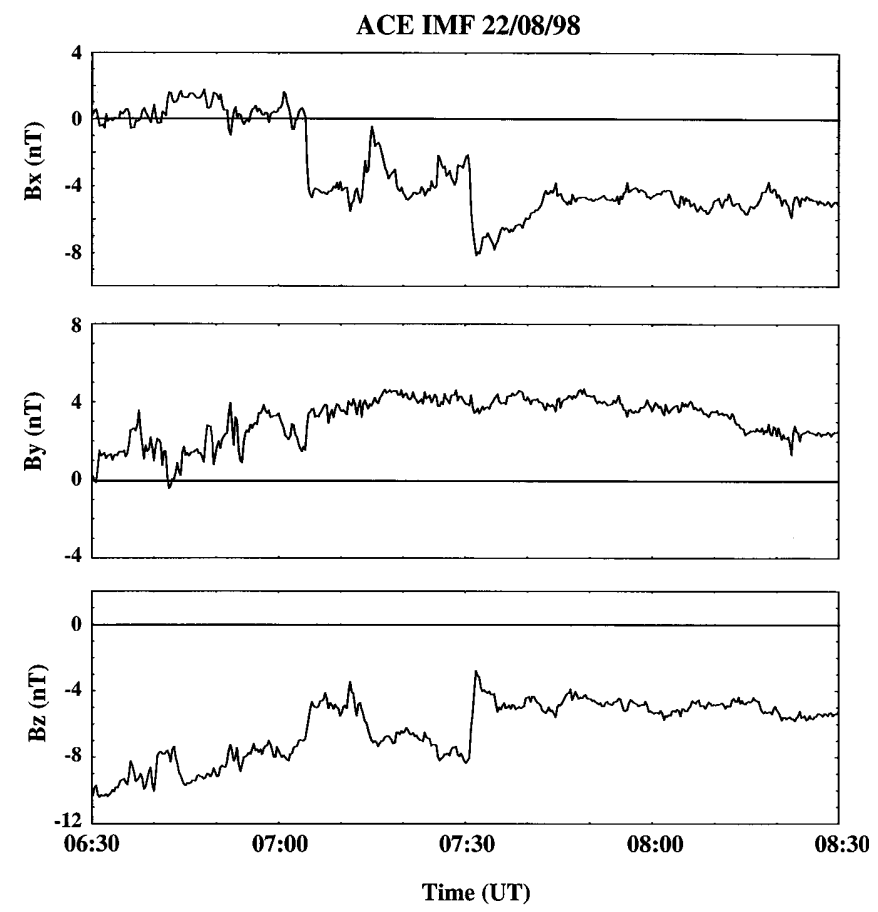

Fig. 3. $B x, B y$ and $B z$ components of the Interplanetary Magnetic Field measured by the ACE satellite upstream in the solar wind between 0630 and 0830 UT 


\section{August 1998}

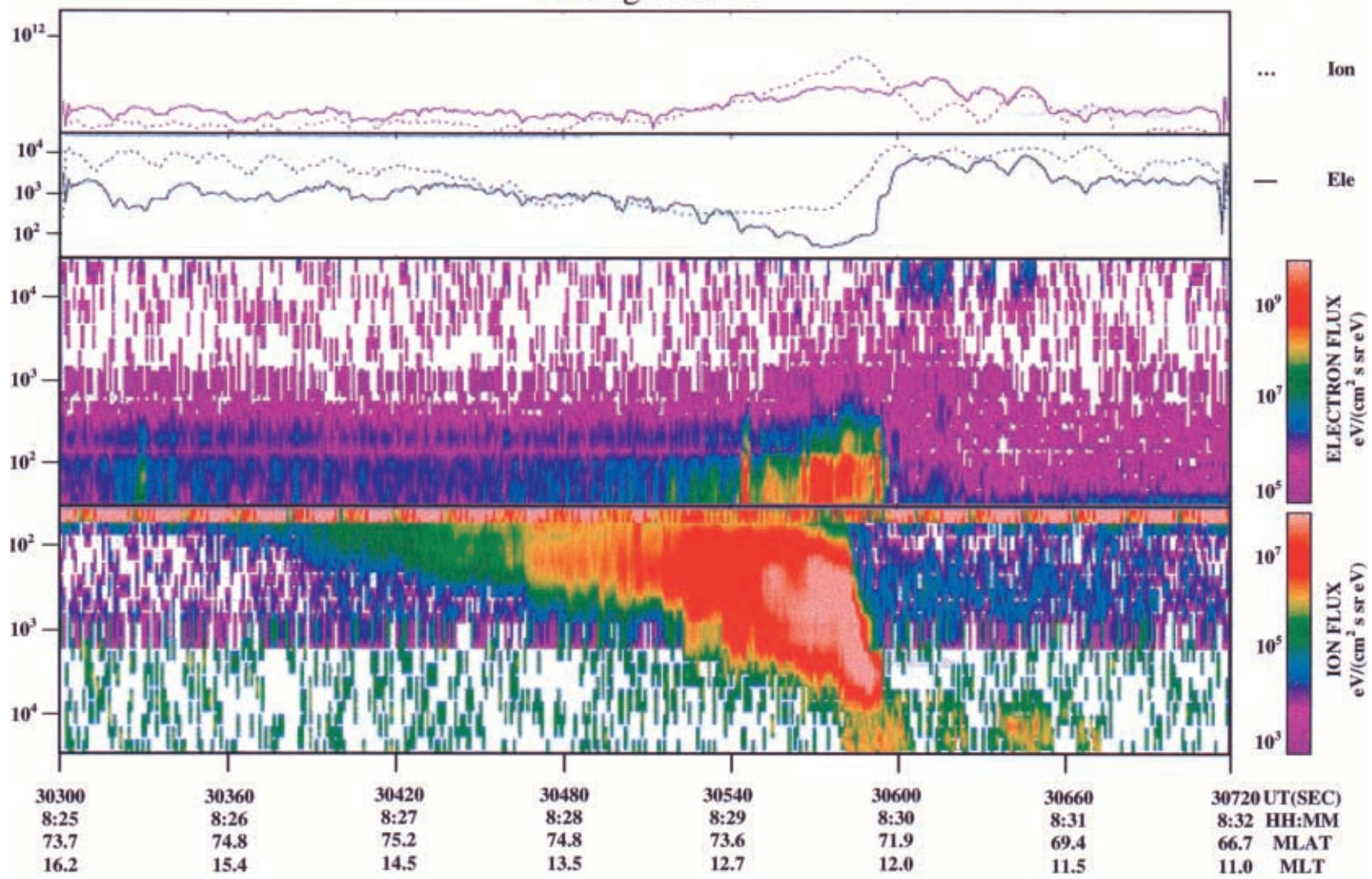

Fig. 4. Electron and ion flux spectra for the pass of the DMSP F14 satellite at around 0830 UT (lower two panels). The energy scales are in the opposite senses for the two panels, with the electron energies

being largest at the top of the electron flux panel but the ion energies largest at the bottom of the ion flux panel

energies $\sim 10^{2} \mathrm{eV}$ between $72.1^{\circ}$ and $73.6^{\circ}$ MLAT. Of particular relevance to the current study is the ion dispersion signature that is indicative of equatorial reconnection. This feature can be seen extending from a sharp equatorward edge near $72.0^{\circ}$ MLAT to a northern extremity at about $75.0^{\circ}$ MLAT. The mapping of the trajectory is illustrated in Fig. 5 on a MLAT versus MLT grid. The region of ion energy dispersion is shown by the shaded triangle whose base indicates the high-energy cutoff and apex illustrates the extent of the low-energy tail. Also shown in Fig. 5 is the $350 \mathrm{~km}$ intersection of the ESR beam between 0800 and 0840 UT. Comparison of the dispersion region with the ESR field-of-view near the Fregion peak reveals that the ion dispersion signature was mainly at latitudes equatorward of those observed by the radar. An earlier pass of the DMSP F13 satellite at about 0806 UT followed an approximately east-to-west trajectory. The observations during this pass also exhibited the signature of ion energy dispersion, the location of which is mapped on Fig. 5. Although widely separate in MLT and separated in UT by some 25 min, good general agreement is seen between the latitude of the dispersion regions observed by the two satellite passes, supporting the interpretation that the reconnection footprint and associated precipitation were equatorward of the ESR observations.

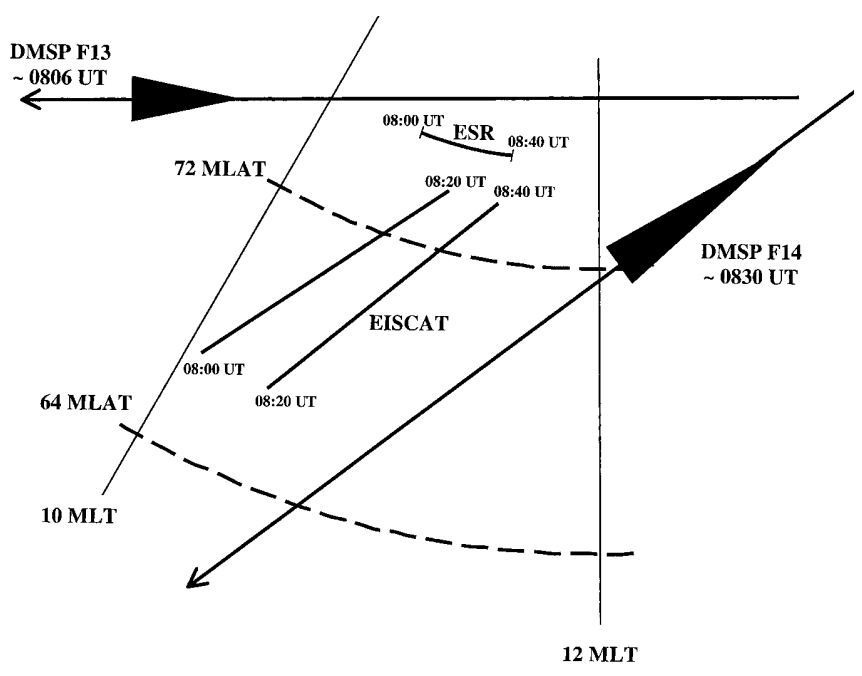

Fig. 5. Plot showing the mapping of the observations on a geomagnetic latitude versus MLT grid. The trajectories of DMSP satellite passes at around 0806 and 0830 UT are shown with the dispersion signatures measured by the particle detectors marked by the black triangles. The base of the triangles indicates the high-energy cut-off of the signatures and the apex the extent of the tail of softer precipitation. Also shown are the intersection at $350 \mathrm{~km}$ of the ESR radar beam between 0800 and 0840 UT and the $350 \mathrm{~km}$ beam intersection of the mainland radar for the scans starting 0800 and $0820 \mathrm{UT}$ 


\subsection{CUTLASS Iceland radar}

Selected frames of the line-of-sight velocities measured by the European SuperDARN CUTLASS radar in Iceland between 0800 and 0840 UT are shown in Fig. 6 . The occurrence of velocity measurements north of $70^{\circ} \mathrm{N}$ during this time interval showed clear temporal variations, attributed to variations in the intensity of backscatter from the F-region. Figure 6a for 0806:30 UT, typical of the early times in the interval, shows no evidence of backscatter from the F-region. At 0808:47 UT backscatter began to be detected from a region north of $70^{\circ}$ MLAT, between about $80^{\circ}$ and $98^{\circ}$ MLON. This developed rapidly into a substantial patch of backscatter with flows sometimes exceeding $800 \mathrm{~ms}^{-1}$ away from the radar. A typical frame, for 0812:14 UT, is illustrated in Fig. 6b. By 0817:58 UT the intense backscatter had subsided into a distribution reminiscent of that in Fig. 6a. A second, albeit weaker, region of increased backscatter occurred between 0821:24 and 0824:51 UT that was again north of $70^{\circ}$ MLAT but at longitudes between 75 and $90^{\circ}$. Figure $6 \mathrm{c}$ for 0823:42 UT is representative of this time period and shows flows away from the radar with velocities greater than $600 \mathrm{~ms}^{-1}$. A third period of backscatter to the north of $70^{\circ} \mathrm{N}$ started at $0832: 53$ UT and continued to the end of the data record. A typical frame for the backscatter after its growth phase is shown in Fig. 6d for 0838:37 UT where the region extends in longitude from about 75 to $98^{\circ}$ MLON.

\subsection{EISCAT mainland radar}

Observations by the EISCAT mainland radar $\left(69.6^{\circ} \mathrm{N}\right)$ were co-ordinated with those of ESR in the OMOT UK Special Programme experiment. The mainland radar observed in scans in the geographic meridian with a cycle time of $20 \mathrm{~min}$. During each scan the Tromsø transmitter beam moved from zenith to an elevation of $20.7^{\circ}$ to the north with latitudinal steps of $0.125^{\circ}$ near the F-region peak, and a dwell time of $20 \mathrm{~s}$ at each pointing direction. At the end of the scan the beam was rapidly moved back to zenith for the start of the next cycle. Remote site observations at Kiruna in Sweden and Sodankylä in Finland intersected the transmitter beam at an altitude of $300 \mathrm{~km}$. The intersection of the Tromsø scan plane with an altitude of $350 \mathrm{~km}$ is shown in Fig. 5 for the two scans between 0800 and 0840 UT.

Electron temperatures for the scans starting at 0800 and 0820 UT are shown in the two panels of Fig. 7. Of particular interest is the region of significantly enhanced temperatures, to the north of about $75^{\circ}$ geographic latitude, $72^{\circ}$ MLAT. The southern edge of this region broadly coincides in latitude with that of the equatorward edge of the ion energy dispersion observed by the DMSP F14 satellite. It can also be noted that the EISCAT radar was observing this region of enhanced temperatures in the first scan shown here at the time of the first burst of HF backscatter measured by the Iceland radar between 0809 UT and 0818 UT. In addition, the elevated temperatures seen in the second scan starting at 0820 UT were measured at the time of the third backscatter interval that began at about 0833 UT. At the time of the second burst of backscatter between 0821 UT and 0825 UT the EISCAT mainland radar was observing close to zenith, well to the south of high electron temperatures produced by the soft precipitation.

The electron densities measured during the scans starting at 0800 and 0820 UT are presented in Fig. 8. In general, these show the solar-produced ionosphere extending from the south, with a peak height at about $300 \mathrm{~km}$. However, at the northernmost elevations there is also evidence in the $\mathrm{F}$ layer of increasing densities that attain values that are well-above the background level of solar production by the end of the second scan. This is attributed to the soft precipitation within the dispersion region. While the feature is close to the edge of the fieldof-view, nevertheless the observations suggest that enhanced densities of some $3.0 \times 10^{11} \mathrm{~m}^{-3}$ are found at altitudes of up to about $370 \mathrm{~km}$, where plasma is long-lived. Softer precipitation is anticipated in the tail of the dispersion to the north of the EISCAT mainland observing region, and it is possible that this would have created ionisation at even higher altitudes.

The eastward and northward components of the tristatic velocities in the plane perpendicular to the geomagnetic field are shown in Fig. 9a, b respectively for the scans starting 0800 and 0820 UT. Whilst care must be taken when interpreting measurements at the northernmost latitudes of the scans because the beams from the three radar sites tend to align, there is no evidence of strong east-west plasma drift at latitudes south of $75^{\circ}$ though a hint of westward flow can be seen in the northern extreme of the field-of-view. The northsouth component shows a clear northward component of some $150 \mathrm{~ms}^{-1}$ at lower latitudes and a trend of gradually increasing velocities to the north that may attain an average of some $300-400 \mathrm{~ms}^{-1}$ at the northern extreme.

\section{Discussion}

Three successive enhancements in electron density were identified by the ESR radar observing in the fieldaligned beam position, while between the features the densities at the layer peak reduced to a background level of some $2.0 \times 10^{11} \mathrm{~m}^{-3}$. The times of the first two enhancements, based on the $2.8 \times 10^{11} \mathrm{~m}^{-3}$ contour, were estimated as 0812-0820 UT and 0824-0830 UT, with the third enhancement coming into the field of view at $0834 \mathrm{UT}$. Maximum densities of approximately $4.0 \times 10^{11} \mathrm{~m}^{-3}$ occurred at about $0817 \mathrm{UT}, 0827 \mathrm{UT}$ and $0837 \mathrm{UT}$, so that the features fall within the broad definition of a polar patch with densities some two-fold above background (Crowley, 1996). The vertical structure of the enhancements, with a sharp gradient on the bottomside, a peak height at about $350 \mathrm{~km}$, and elevated densities extending into the topside, supported this interpretation of the features as polar patches with 


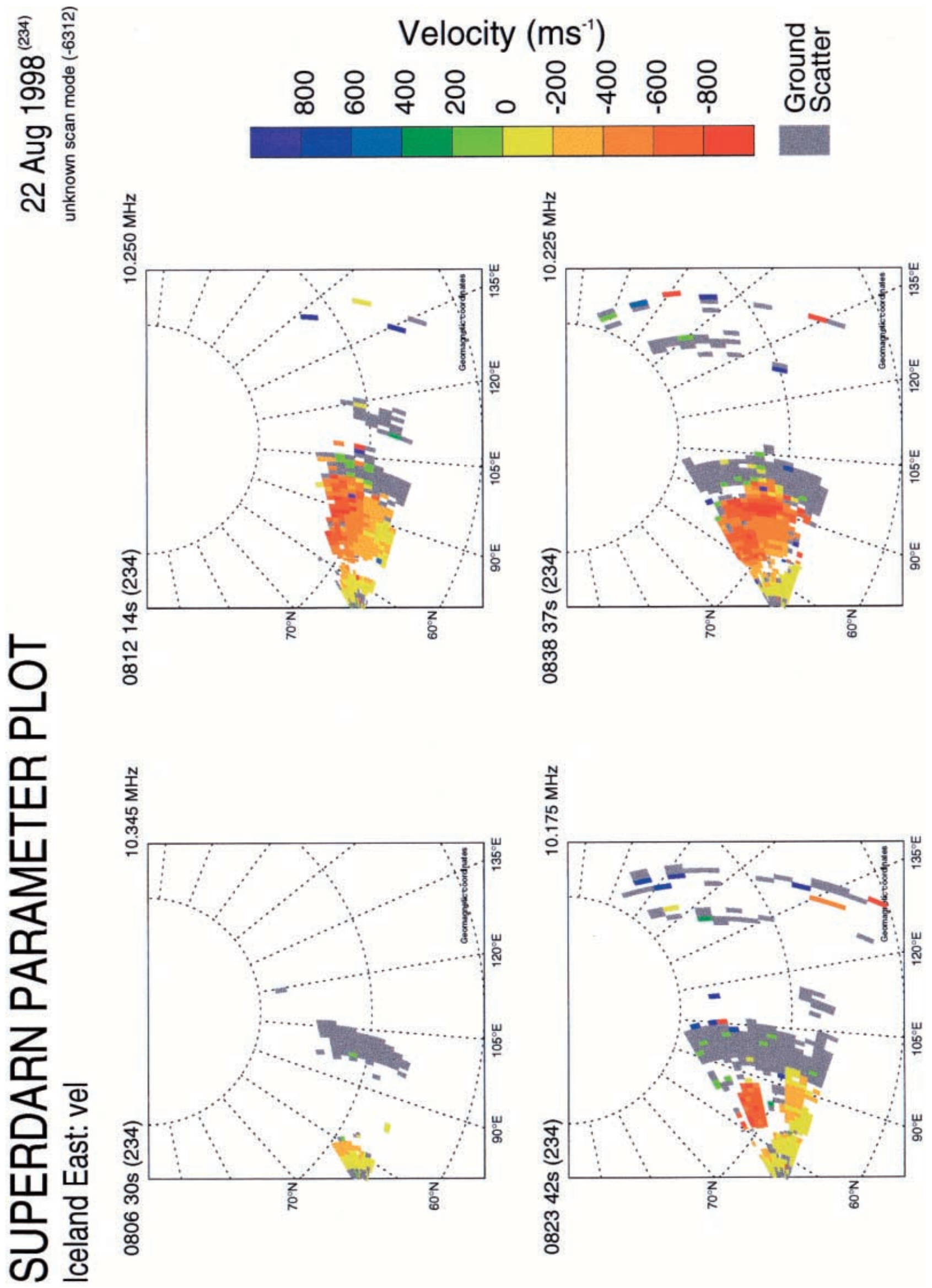


Fig. 6a-d. Line-of-sight velocities measured by the Iceland radar of the CUTLASS SuperDARN facility on a geomagnetic grid for observations at a 0806:30 UT, b 0812:14 UT, c 0823:42 UT and d 0838:37 UT. Positive values represent flows towards the radar (located to the left of the grid) and negative values flows away from the radar

the plasma being mainly at high altitudes where the lifetime could possibly be hours.

The essentially steady electron temperatures observed by ESR suggested that the density enhancements were not produced in situ by soft-precipitation, but rather were structures of cold plasma that had convected into the field-of-view. The composite velocity plot of Fig. 10 shows the line-of-sight velocities measured by the CUTLASS Finland and Iceland radars at about 0812 UT. The colour scales used in the figure for the Iceland site refer to flows towards and away from the Iceland radar and similarly those for the Finland site refer to flows towards and away from the Finland site. Thus the triangular region of backscatter near $70^{\circ}$ MLAT on the left-hand side of the figure relates to the Iceland radar with the red indicating flows away from the radar and the green near $105^{\circ} \mathrm{E}$ showing weaker flows towards the radar. The region of backscatter centred near $75^{\circ}$ MLAT shows flows away from the Finland radar. Lack of significant overlap in the two data sets precludes the estimation of full velocity vectors. Mapped on to the figure are the locations of the dispersion signatures measured by the DMSP satellite passes. The signature for the F13 satellite at about 0806 UT is co-located in latitude with the region of Iceland radar backscatter. The $350 \mathrm{~km}$ intersections of the ESR and the EISCAT mainland radars are also shown. The EISCAT tristatic velocities showed that flows were generally northward at 0812 UT but with the possibility of a westward component at the highest latitudes. Interpretation of the figure suggests that the mainland radar was observing near the region of convergence of the return flows of the dawn and dusk convection cells where the plasma was being drawn poleward towards the ESR radar.

Photo-production is the main source of plasma in the sunlit summer ionosphere. However, the observations presented also showed signatures in the plasma that are characteristic of equatorial reconnection. For example, DMSP satellite particle flux measurements revealed ion dispersion and cusp precipitation (Newell and Meng, 1988) while the EISCAT electron temperatures indicated soft precipitation within the region of dispersion with its sharp equatorward edge (Pryse et al., 2000). Moreover, electron densities within the precipitation region at the northernmost part of the EISCAT mainland scan starting at 0820 UT (Fig. 8) were greater than the solar-produced densities some four degrees latitude to
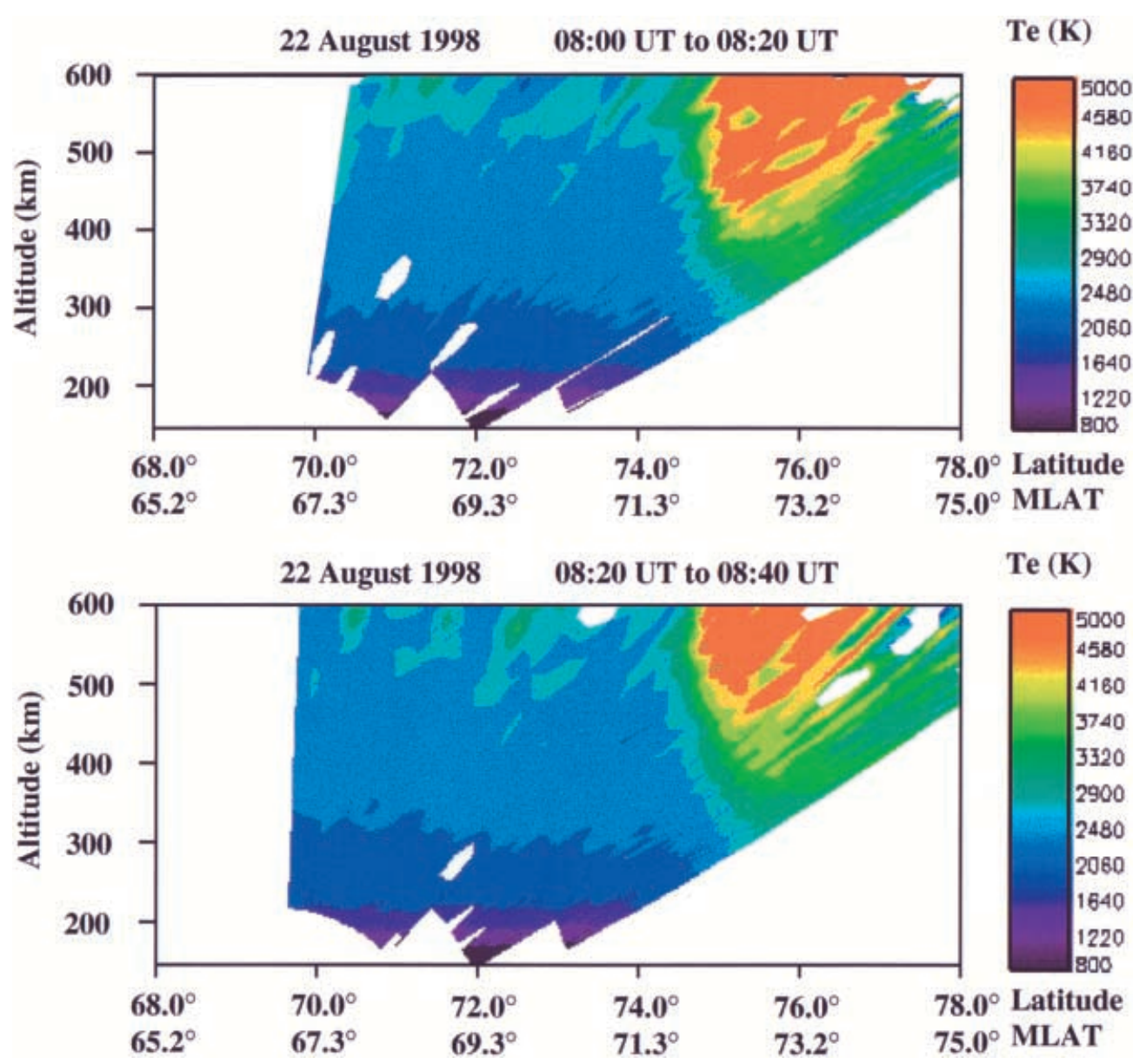

Fig. 7. Electron temperatures measured by the EISCAT mainland radar observing in the OMOT UK Special Programme mode between 0800 and 0840 UT 

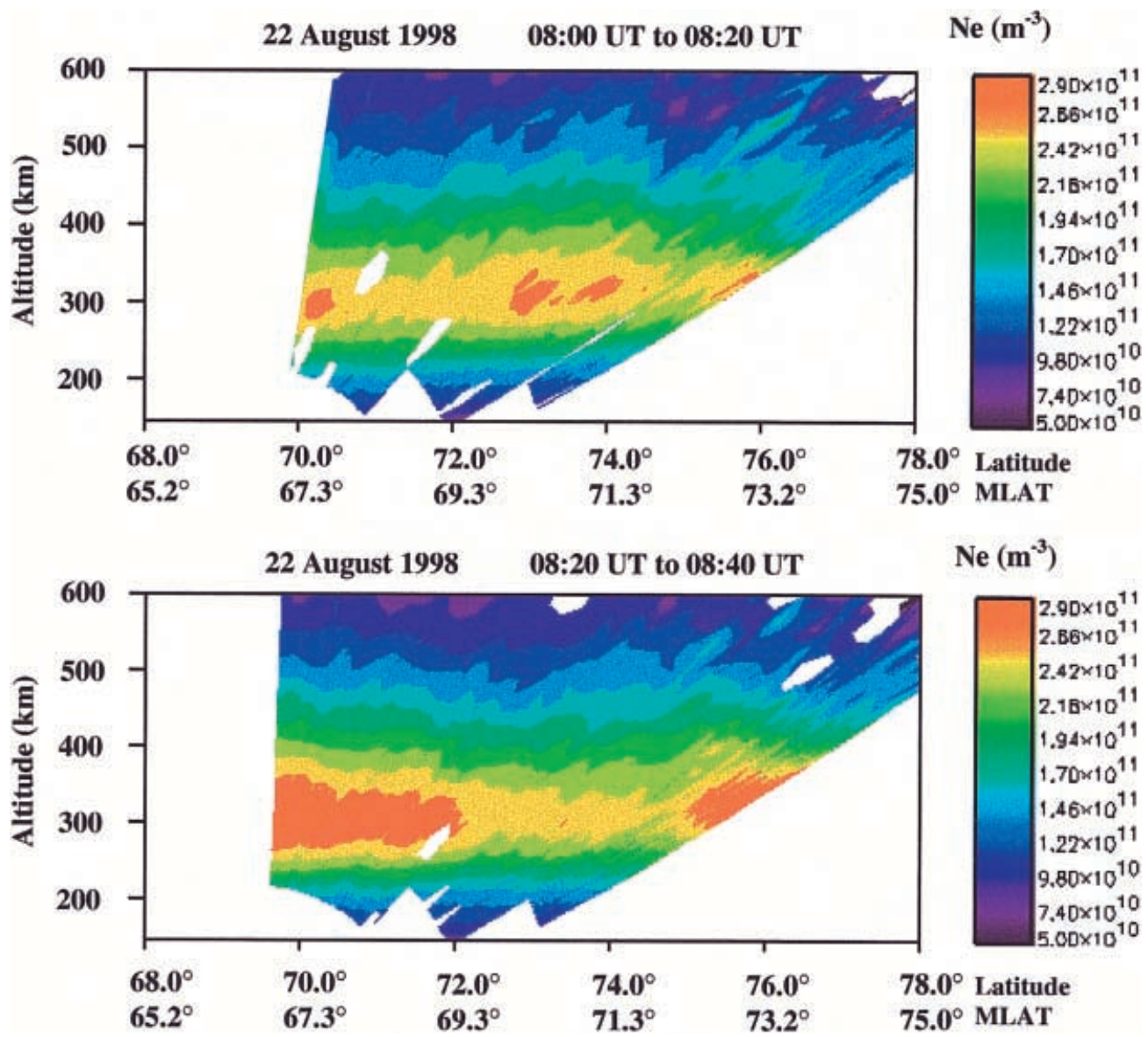

Fig. 8. Electron densities measured by the EISCAT mainland radar observing in the OMOT UK Special Programme mode between 0800 and 0840 UT the south, suggesting that the soft precipitation was creating significant ionisation at the higher latitudes.

The evidence suggests that the cold plasma in the enhancements observed by ESR originates from lower latitudes. It is unlikely that these consist solely of solar ionisation, as it would be necessary to entrain plasma from latitudes significantly south of the radar to attain densities comparable to those observed in the patches. It is more likely that the enhancements comprise photoionisation within which plasma produced by softprecipitation in the dispersion region is superimposed. The cause of the "patchy" nature of the density remains to be resolved. One possible scenario is that there was a tongue of ionisation extending from lower latitudes whose longitudinal location was being modulated by changes in IMF By. The ESR radar, observing in only one pointing direction, would thus observe patch-like variations in $\mathrm{Ne}$ as the tongue moved in and out of the beam. However, Fig. 3 shows that $B y$ with an appropriate time delay was relatively constant throughout the period of interest. An alternative possible mechanism involves temporal structuring of the precipitation, resulting in three enhancements that are carried by the anti-Sunward flow into the ESR field-of-view. Support for this mechanism is provided by the CUTLASS Iceland radar. Three intervals were identified in the measurements of clear increased backscatter within the latitudinal range of the DMSP ion dispersion signature at approximately 0809-0818 UT, 0821-0825 UT and after $0833 \mathrm{UT}$. It is possible that these increases were linked to periods of more intense precipitation, with either the $\sim 15 \mathrm{~m}$ scale irregularities required for the HF backscatter being embedded within the precipitating structures or being produced by the $\mathbf{E} \times \mathbf{B}$ instability when plasma is convected up the gradients of the largescale electron density enhancements produced by the precipitating particles. On the former interpretation it is likely that the precipitation and backscatter will occur essentially simultaneously. However, in the latter case there would be a lag between the precipitation and the backscatter while a sufficient gradient was formed for consequent instability and growth of the decametrescale irregularities. Although the location of the observed backscatter was west of the EISCAT field-ofview it is reasonable to expect that the precipitation intensifications were extended in longitude along the reconnection X-line. This interpretation is confirmed by the two DMSP passes that both showed the leading edge of the precipitation at similar magnetic latitude though separated by more than $2 \mathrm{~h}$ of magnetic local time and 25 min UT. Comparisons of the times of the first and second intervals of Iceland backscatter with the times of the observations of the first two patches by the ESR radar show reasonable agreement, with the onset of backscatter leading the $2.8 \times 10^{11} \mathrm{~m}^{-3}$ threshold selected for the density by some $3 \mathrm{~min}$. With this delay and a poleward convection speed $\sim 250 \mathrm{~ms}^{-1}$, measured by the EISCAT mainland radar, the source of 
a

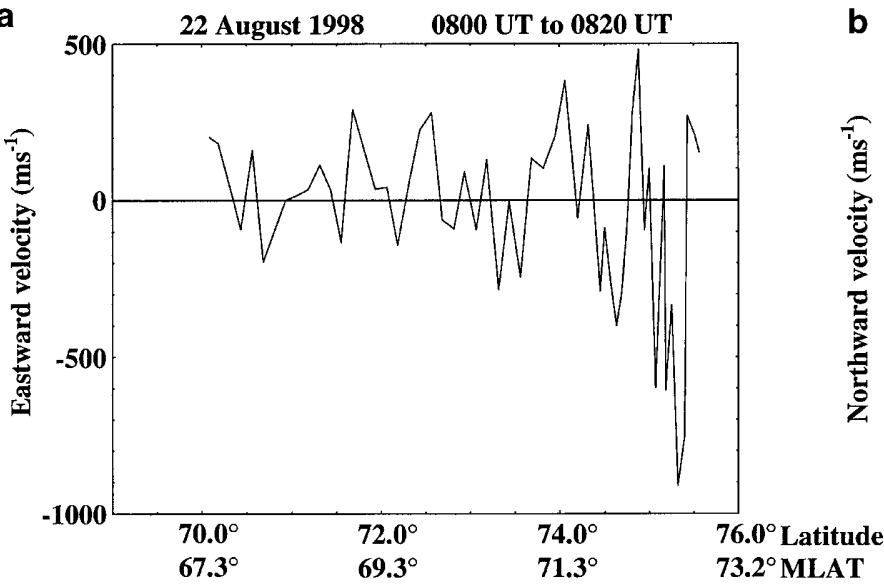

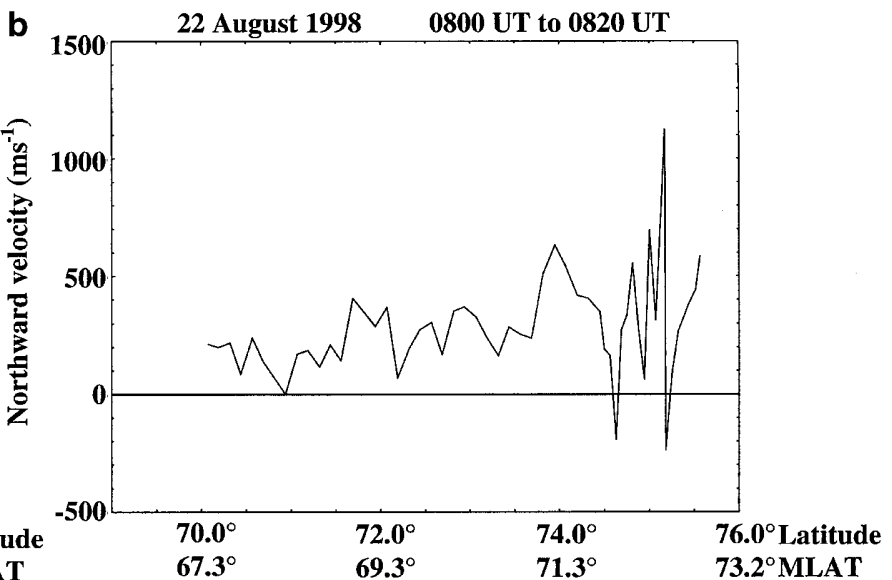
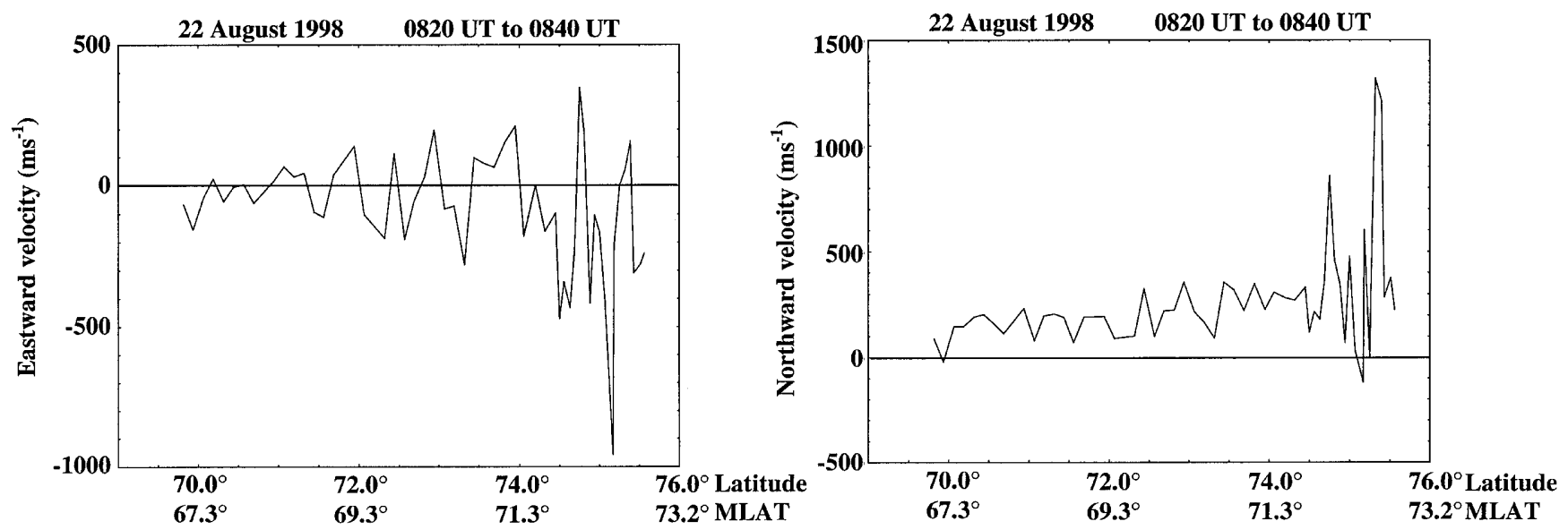

Fig. 9a, b. The a eastward and $\mathbf{b}$ northward components of the tristatic velocity in the plane perpendicular to the geomagnetic field, measured by the mainland EISCAT radar between 0800 and 0840 UT

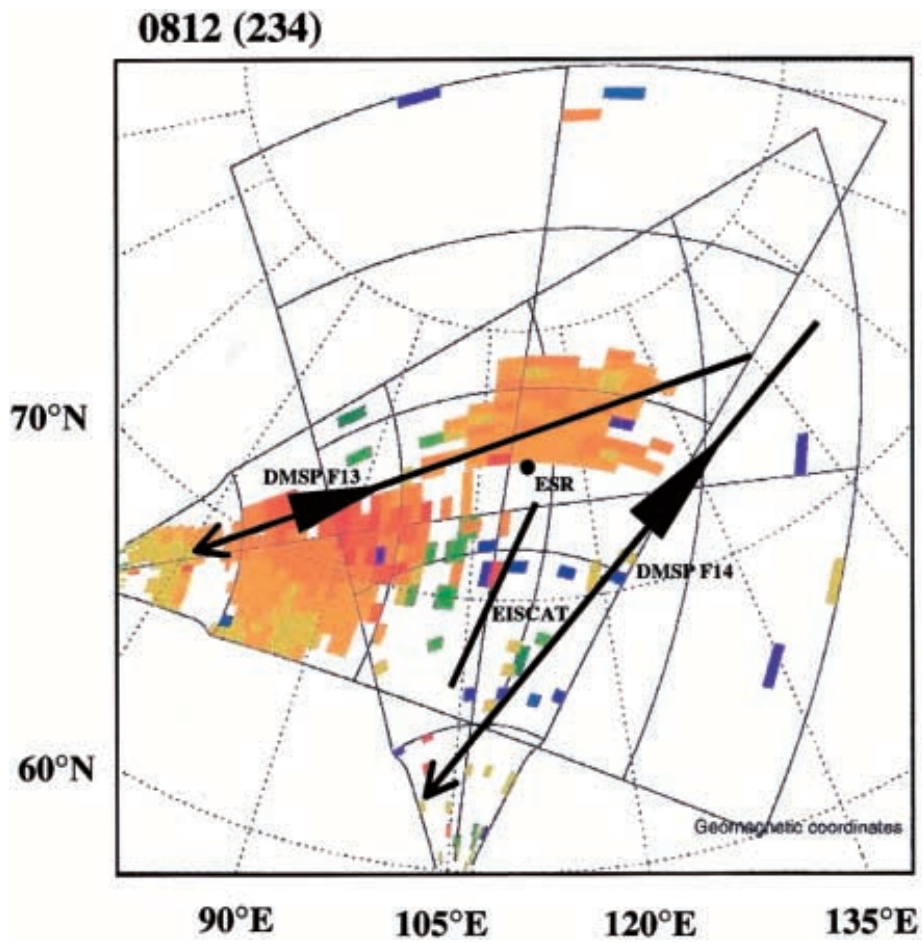

Fig. 10. Composite plot showing the lineof-sight velocities measured by both the

200

$\mathbf{0}$

$-200$

$-400$

$-600$

$-800$ Iceland and Finland CUTLASS radars on a geomagnetic grid at about 0812 UT. Positive values represent flows towards a radar and negative values flows away from the corresponding radar. The triangular region of backscatter near $70^{\circ}$ MLAT on the lefthand side of the figure relates to the Iceland radar with the red indicating flows away from the radar and the green near $105^{\circ} \mathrm{E}$ flows towards the radar. The region of backscatter centred near $75^{\circ}$ MLAT shows flows away from the Finland radar. Also shown is the mapping of the locations of the dispersion signatures for the DMSP satellite passes at around 0806 UT and 0830 UT by the black triangles, and the $350 \mathrm{~km}$ intersections of the ESR and EISCAT mainland radar beams 
enhanced ionisation is likely to be at latitudes within the dispersion region.

Maximum densities in the enhancements observed by the ESR radar were approximately $4.0 \times 10^{11} \mathrm{~m}^{-3}$, about double that of the assumed background level. For the first enhancement, the time taken for the densities to increase from $2.8 \times 10^{11}$ to $4.0 \times 10^{11} \mathrm{~m}^{-3}$ was about $5 \mathrm{~min}$, while for the second feature it was some $3 \mathrm{~min}$. With the knowledge that the flow toward the ESR radar was reasonably constant in the vicinity of the cusp precipitation, the time required for the increase in the plasma density can be taken as representative of the actual growth time of plasma due to a source at lower latitude at an earlier time. The growth rates are therefore estimated as $4 \times 10^{8} \mathrm{~m}^{-3} \mathrm{~s}^{-1}$ for the first enhancement and $7 \times 10^{8} \mathrm{~m}^{-3} \mathrm{~s}^{-1}$ for the second. Within the limitations of the estimates, these magnitudes are in broad agreement with a growth rate $\sim 8 \times 10^{8} \mathrm{~m}^{-3} \mathrm{~s}^{-1}$ inferred for an altitude of $300 \mathrm{~km}$ from Fig. 7 of the modelling study of Millward et al. (1999), where the ionosphere was subject to both ion and electron precipitation in the cusp region which resulted in plasma near the F2 peak produced predominantly by the incoming electrons.

The observations suggest that the soft precipitation in the cusp region was modulated by periods of more intense precipitation activity that may have caused the electron density patches. It is possible that the bursts of increased precipitation with repetition time of some 10 min can be attributed to a pulsating cusp (Lockwood et al., 1993), believed to be associated with flux transfer events (Lockwood and Wild, 1993). Lockwood and Carlson (1992) proposed that the production of polar patches may be linked to FTEs, but suggested that polar-cap expansion during the events took solarproduced plasma into the high-latitude regime. However, in the current study intake of photo-ionisation is unlikely to be the sole cause of the observed patches. A second possibility is that the modulation is related to changes in the IMF orientation. It can be seen from Fig. 3 that three bays occur in the IMF $B x$ with the component showing three small negative enhancements between 0704 UT and $0740 \mathrm{UT}$. There is also some evidence for small variations in the IMF $B z$, during which the component becomes less negative, that are reasonably in-step with the changes in $B x$. Comparisons for the start times of the three bays with the start times of the F-region CUTLASS Iceland backscatter suggest the slightly different delays of 65, 66 and $63 \mathrm{~min}$ respectively for the propagation of the effects of the magnetospheric processes to the ionosphere, shorter than the estimated value. Hence, a possible interpretation of the results in light of the variations in IMF is that changes in IMF orientation lead to changes in the location of the reconnection site in the magnetosphere where the geomagnetic field and IMF must be antiparallel. This in turn may move the reconnection site to a region of different particle energy distribution, resulting in the observed modulation of the precipitating particles. Chisham et al. (2000) highlight the effect of IMF $B x$, with the IMF component and the dipole tilt of the magnetosphere influencing the location of the reconnection site.

\section{Conclusions}

A sequence of three electron density enhancements that satisfy criteria for polar patches have been observed by the ESR radar in the noon magnetic sector under IMF conditions conducive to equatorial reconnection. The enhanced densities were not produced in situ in the radar beam, but multi-instrument observations suggested that their source was upstream in the plasma convection flow at lower latitudes. The durations of the enhancements were in broad agreement with those of increases in F-region backscatter observed by the CUTLASS Iceland radar, with the leading edge of the events observed by ESR lagging the onset of those seen by the HF radar by about $3 \mathrm{~min}$. With the likelihood of increased precipitation accompanying the increased backscatter, it is proposed that the polar patches were created by intensifications of soft-particle precipitation within the cusp region in-keeping with the conclusion of Walker et al. (1999). Whilst it is not possible to be conclusive about the driving mechanism of the temporal variation in the precipitation, it is likely that it is due to temporal magnetospheric changes. In particular, it is possible that variations in IMF orientation lead to changes in the location of the reconnection site and hence in the energy distribution of the precipitating particles.

Acknowledgements. Financial support for the project has been provided by the UK Particle Physics and Astronomy Research Council under grant PPA/G/S/1997/00269. EISCAT is an international facility supported by the national science councils of Finland, France, Germany, Japan, Norway, Sweden and the United Kingdom. The DMSP data were provided by F. Rich at AFRL, Hanscom, USA. The CUTLASS radar is a UK national facility funded by the Particle Physics and Astronomy Research Council; the data used here have been supplied by T. Yeoman. The ACE data were provided by $\mathrm{N}$. Ness and obtained from the CDAWeb, NASA. AMS acknowledges receipt of a PPARC research studentship.

Topical Editor M. Lester thanks T. Ogawa and another referee for their help in evaluating this paper.

\section{References}

Buchau, J., and B. W. Reinisch, Electron density structures in the polar F-region, Adv. Space Res., 11(10), 29-32, 1991.

Buchau, J., B. W. Reinisch, E. J. Weber, and J. G. Moore, Structure and dynamics of the winter polar cap F-region, Radio Sci., 18, 995-1010, 1983.

Buchau, J., E. J. Weber, D. N. Anderson, H. C. Carlson, Jr., J. G. Moore, B. W. Reinisch, and R. C. Livingston, Ionospheric structures in the polar cap: their origin in relation to $250 \mathrm{MHz}$ scintillation, Radio Sci., 20, 325-338, 1985.

Chisham, G., M. Pinnock, A. S. Rodger, and J.-P. Villain, Hightime resolution conjugate SuperDARN radar observations of the dayside convection response to changes in IMF By, Ann. Geophysicae, 18, 191-201, 2000.

Crowley, G., Critical review of ionospheric patches and blobs, in URSI Review of Radio Science 1993-1996, Ed W.R. Stone, 619648, 1996. 
Lockwood, M., and H. C. Carlson, Jr., Production of polar cap electron density patches by transient magnetopause reconnection, Geophys. Res. Lett., 19, 1731-1734, 1992.

Lockwood, M., and M. N. Wild, On the quasi-periodic nature of magnetopause flux transfer events, J. Geophys. Res., 98, 5935$5940,1993$.

Lockwood, M., W. F. Denig, A. D. Farmer, V. N. Davda, S. W. H. Cowley, and H. Lühr, Ionospheric signatures of pulsed reconnection at the Earth's magnetopause, Nature, 361, 424-428, 1993.

McCrea, I. W., G. O. L. Jones, and M. Lester, The BEAN experiment - An EISCAT study of ion temperature anisotropies, Ann. Geophysicae, 13, 177-188, 1995.

Millward, G. H., R. J. Moffett, H. F. Balmforth, and A. S. Rodger, Modelling the ionospheric effects of ion and electron precipitation in the cusp, J. Geophys. Res., 104, 24 603-24 612, 1999.

Newell, P. T., and C.-I. Meng, The cusp and cleft/boundary layer: low altitude identification and statistical local time variation, J. Geophys. Res., 93, 14 549-14 556, 1988.

Pederson, T. R., B. G. Fejer, R. A. Doe, and E. J. Weber, Incoherent scatter radar observations of horizontal F-region plasma structure over Sondrestrom, Greenland, during polar cap patch events, Radio Sci., 33, 1847-1866, 1998.

Pryse, S. E., A. M. Smith, I. K. Walker, and L. Kersley, Multiinstrument study of footprints of magnetopause reconnection in the summer ionosphere, Ann. Geophysicae, 18, 1118-1127, 2000.

Rodger, A. S., M. Pinnock, J. R. Dudeney, J. Watermann, O. de la Beaujardiere, and K. B. Baker, Simultaneous two hemisphere observations of the presence of polar patches in the nightside ionosphere, Ann. Geophysicae, 12, 642-648, 1994a.

Rodger, A. S., M. Pinnock, J. R. Dudeney, K. B. Baker, and R. A. Greenwald, A new mechanism for polar patch formation, J. Geophys. Res., 99, 6425-6436, 1994b.

Sojka, J. J., and R. W. Schunk, A theoretical study of the production and decay of localised electron density enhancements in the polar ionosphere, J. Geophys. Res., 91, 3245-3253, 1986.

Sojka, J. J., M. D. Bowline, R. W. Schunk, D. T. Decker, C. E. Valladares, R. Sheehan, D. N. Anderson, and R. A. Heelis, Modelling polar cap F-region patches using time varying convection, Geophys. Res. Lett., 20, 1783-1786, 1993.

Sojka, J. J., M. D. Bowline, and R. W. Schunk, Patches in the polar ionosphere: UT and seasonal dependence, J. Geophys. Res., 99, 14 959-14 970, 1994.

Valladares, C. E., S. Basu, J. Buchau, and E. Friis-Christensen, Experimental evidence for the formation and entry of patches into the polar cap, Radio Sci., 29, 167-194, 1994.

Walker, I. K., J. Moen, L. Kersley, and D. A. Lorentzen, On the possible role of cusp/cleft precipitation in the formation of polar-cap patches, Ann. Geophysicae, 17, 1298-1305, 1999.

Weber, E. J., J. Buchau, J. G. Moore, J. R. Sharber, R. C. Livingston, J. D. Winningham, and B. W. Reinisch, F-layer ionization patches in the polar cap, J. Geophys. Res., 89, 16831694, 1984. 